\title{
CONTENT ANALYSIS OF COVID-19 MESSAGES ON SELECT WHATSAPP GROUPS: A NIGERIAN PERSPECTIVE
}

\author{
Umefien Dakoru Epepe \\ Department of Communication Studies \\ National Institute for Nigerian Languages \\ Aba, Abia State, Nigeria \\ umefien75@gmail.com \\ +2348036713301
}

\begin{abstract}
This study examined novel coronavirus (COVID-19) messages on select Nigeria-based WhatsApp groups. Viewed through the lens of the Rumour Theory, the study applied content analysis and social semiotics (multimodal discourse analysis) methods. Data were elicited from three purposively selected WhatsApp groups, using the constructed and continuous weeks approach. The sample covered 6 weeks (42 days), spread across March, April, and May 2020. Findings from the content analysis showed that texts, comments, and linked message on COVID-19, had the highest frequency. The frequency of messages peaked in March and steeply tapered downwards in April and May 2020. The multimodal discourse analysis demonstrated a preponderance of messages about vaccines, treatment, prevention, lockdown, and conspiracy theories. A significant number of COVID-19 messages were based on rumours and misinformation from spurious sources, with a few from credible sources. The study recommended that to help flatten the misinformation curve, timely, unambiguous and accurate COVID-19 information should be provided from official sources.
\end{abstract}

Keywords: COVID-19; Messages; Misinformation; Nigeria; WhatsApp;

\section{INTRODUCTION}

Advances in Web.2.0 technologies and the ubiquity of smartphones have brought extraordinary changes to the communication landscape. As recent observation shows, breaking news most times first appears on the interactive web. For example, in December 2019, the World Health Organisation (WHO) broke the news of the novel coronavirus (COVID-19) outbreak in Wuhan, China on its website (WHO, 2020). Before long, social media platforms such as WhatsApp were inundated with COVID-19 messages. This did not come as a surprise, since WhatsApp currently has over 2 billion active users across the globe (WhatsApp, 2020). With these statistics, WhatsApp soon began to play a leading role in information dissemination on COVID-19.

With the deluge of messages circulating, WhatsApp came under heavy criticisms for enhancing the spread of misinformation. As Mehta (2020, para. 1) said, "The Coronavirus outbreak is spreading rapidly, and so is misinformation related to the pandemic." To help flatten the curve of misinformation, in March 2020, WHO, leveraged the critical mass usage of WhatsApp by launching WHO Health Alert. A couple of years ago, Shahid (2018) mentioned that WhatsApp has become a substitute for Short Message Service (SMS) in developing countries. In particular, anecdotal evidence suggests that WhatsApp has become a leading messaging platform in Nigeria, with 53\% of internet users (Boyd, 2019). As the Nigeria Centre for Disease Control (NCDC) confirmed the index case of COVID-19 on 27 February 2020, WhatsApp was one of the platforms extensively deployed to provide information to Nigerians. This upward trend may be attributable to the fact that WhatsApp operates a cost-effective, multimodal interactive system in the form of text, call, video, audio, and live streaming. 
Studies exist on WhatsApp and information dissemination in other contexts (e.g., Seufert, Schwind, Hoßfeld \& Tran-Gia, 2015; Shahid, 2018). There is, arguably, a paucity of research focusing on group-based WhatsApp messages on COVID-19 within the Nigerian context. Therefore, this exploratory study would contribute to the bridging of this gap in the literature, as it analysed COVID-19 messages on select Nigeria-based WhatsApp groups. The aim is to unearth the frequency, dominant communication formats, and credibility of COVID-19 messages on the select WhatsApp groups.

\section{OBJECTIVES}

The objectives of the study are to:

1. Find out the frequency of COVID-19 messages on select WhatsApp groups;

2. Ascertain the dominant format used in disseminating COVID-19 message on select WhatsApp groups;

3. Ascertain the month with the highest number of COVID-19 messages on select WhatsApp groups;

4. Find out the credibility of messages on the selected WhatsApp groups.

\section{LITERATURE REVIEW}

Anecdotal and empirical literature abounds on the increasing role of WhatsApp in information and misinformation dissemination. This section briefly reviews pertinent literature.

\section{WHATSAPP: INFORMATION OR MISINFORMATION GATEWAY FOR COVID- 19?}

WhatsApp is an interactive mobile app, founded by Jan Koum and Brian Acton (WhatsApp Website, 2020). Although Facebook bought WhatsApp in 2014 (WhatsApp Website, 2020), it had maintained its original name. According to Barhoumi (2015, p.222), "WhatsApp (from the English phrase 'What's up?' meaning 'what's new?'), is an instant messaging application for smartphones". Nonetheless, this has changed over the years. It is now possible to access it on internet-enabled computers via WhatsApp Web.

Several scholars have investigated WhatsApp as a communication tool. Seufert et al. (2015) investigated group-based communication in WhatsApp. They found that the app has become an important means of communication. Shahid (2018) demonstrated that WhatsApp was an effective and affordable communication platform, useful for group communication. Nonetheless, WhatsApp is often blamed for enabling the spread of misleading information. Observably, WhatsApp's potential of spreading misinformation was amplified at the peak of the COVID-19 pandemic.

As Davies (2020, para. 2) stated, "the spread of misinformation in many ways mimics how COVID-19 itself moves through societies, from individual to individual, group to group". He added that crisis comes with a surge in misinformation, which thrives because it acts on our hopes and fears and validates our biases. Kazeem (2020, headline) aptly captured it thus, "Nigeria's biggest battle with coronavirus will be beating misinformation." This is enhanced by the town crier function of the 'Forward' feature of WhatsApp. Without a doubt, the speed with which the 'Forward' feature of WhatsApp spreads messages is phenomenal.

Acknowledging the risk of misinformation, WhatsApp made efforts to flatten the curve. For instance, with certain messages, the operators of WhatsApp restricted the group sizes to 256 users, reduced the number of times a message could be "Forwarded" to five, and flagged th 
as "forwarded" in the first place (Davies, 2020; WhatsApp, 2020). Woog, a spokesperson for WhatsApp, said, "WhatsApp is an important tool for health workers to coordinate and we have engaged health ministries around the world to provide simple ways for citizens to receive accurate information about the virus (as cited in Romm 2020, para.9)." Again, WhatsApp partnered with WHO to provide information to reach over 2 billion global audiences on the pandemic (WhatsApp, 2020; WHO, 2020).

Nevertheless, Matiashe (2020) opined that a major challenge for governments, public health authorities and ordinary citizens around the world would be how to cope with the devastating amount of daily information on the pandemic. As the messages continued to flood media spaces, it became increasingly difficult to separate the facts from the rumours, thereby heightening fear and anxiety among the populace.

\section{THEORETICAL UNDERPINNING}

The novelty of the COVID-19 pandemic brought with it, a deluge of messages. This left room for uncertainty and ambiguity, making rumour thrive, particularly on social media platforms. Accordingly, this study viewed COVID-19 messages on WhatsApp through the lens of the Rumuor Theory.

\section{RUMOUR THEORY}

There is evidence that rumour research began to gain attention in the first quarter of the 20th century (e.g., Hart, 1916; Stern, 1902). However, it was perhaps, the influential works of Knapp (1944) and Allport and Postman (1946, 1947), who studied the destructive effects of rumour in World War II, that set the tone for rumour studies. Knapp defined "Rumor", 'as a proposition for belief (sic) of topical reference disseminated without official verification (as cited in Rosnow, Esposito \& Gibney 1988).'

Allport and Postman (1947) introduced the "basic law of rumor", which postulated that the power of 'rumor' changes with topic importance and ambiguity. Allport and Postman (1946) believed that rumour is starts and travels in a homogenous social medium under the robust interests of the persons involved in the transmission. They expatiated that 'rumor' thrives on lack of news and "flies thickest when news is most plentiful (Allport \& Postman, 1946, p. 501)." To checkmate rumour, people must be given the "most accurate possible news, promptly and completely (Allport \& Postman, 1946)".

Rumour theory has enjoyed wide application in the fields of psychology (Rosnow, 1980), sociology (Shibutani, 1966) and communication-Twitter (Oh, Kwon \& Rao 2010), and discussion groups (Bordia \& DiFonzo, 2004). Oyewo (2007) stated that "Rumour mongering constitutes one of the most common, but least understood modes of social Interaction". Since the COVID-19 pandemic is of high importance and high ambiguity because of its novelty, it is arguably susceptible to rumour peddling. Against this backdrop, rumour theory is apt for studying COVID-19 messages on WhatsApp groups.

\section{METHODOLOGY}

The study adopted content analysis, using the instrument of manual coding and social semiotics (using multimodal discourse analysis). The research methodology elicited quantitative and qualitative data on three purposively selected WhatsApp groups. The content analysis sought to establish the frequency of messages and dominant message formats. Social semiotics attempts to look beyond the words and images in the interpretation of communication output 
This was achieved by reading 'between the lines of visual and verbal communication, as recommended by Kress and van Leeuwen (2006). This method provides an understanding of the power and meaning of messages to establish the relationship between visual and language of the multimodal text (Baykal 2016; Kress and van Leeuwen, 2006).

In line with digital trends in communication, the study applies the terms, 'Representational meanings', 'Interactive meanings' and 'Composition'(Kress and van Leeuwen 2006), as derivatives of Halliday's (1978) three metafunctions of semantic levels (i.e. ideational, interpersonal and textual). Data were elicited from a sample of selected days based on the continuous and constructed weeks approach (see Table 1) to select 6 weeks (42 days). The study covered the months of March, April and May 2020, representing the peak of the first wave of COVID-19 in Nigeria. Only messages that mentioned COVID-19 in the headline or content were analysed.

Content categories included: texts, video, pictures, links, comments, audio and emoticons. Unit of analysis were words and headlines. Lai and To (2015) stated that social media has become a major part of social life. According to them, converting social media content into information, key concepts, and themes are crucial for generating knowledge and formulating strategies. Therefore, content analysis and social semiotics are relevant in the analysis of the textual and visual representation of COVID-19 messages on WhatsApp.

Table 1

Sample of Continuous and Constructed Weeks/Days (March, April, May 2020)

\begin{tabular}{|c|c|c|c|c|c|c|c|}
\hline \multirow[t]{2}{*}{ Days } & \multicolumn{3}{|c|}{ Continuous Weeks } & \multicolumn{2}{|c|}{$\begin{array}{l}\text { Constructed } \\
\text { Weeks }\end{array}$} & & \multirow[t]{2}{*}{ Total } \\
\hline & March & $\begin{array}{l}\text { Apri } \\
1\end{array}$ & May & March & April & May & \\
\hline Sunday & 22 & 19 & 3 & 15 & 26 & 17 & \\
\hline Monday & 23 & 20 & 4 & 2 & 6 & 11 & \\
\hline Tuesday & 24 & 21 & 5 & 17 & 14 & 19 & \\
\hline Wednesday & 25 & 22 & 6 & 4 & 29 & 27 & \\
\hline Thursday & 26 & 23 & 7 & 19 & 16 & 21 & \\
\hline Friday & 27 & 24 & 8 & 20 & 3 & 1 & \\
\hline Saturday & 28 & 25 & 9 & 7 & 4 & 30 & \\
\hline Total & 7 & 7 & 7 & 7 & 7 & 7 & 42 \\
\hline
\end{tabular}

\section{RESULTS AND DISCUSSION}

Frequency tables and graphs were used to present quantitative data elicited from the content analysis. Multimodal discourse analysis was used to interpret qualitative data, under two subheadings: (a) credible information and (b) misinformation. For privacy concerns, the WhatsApp groups are labelled as Group 1, Group 2 and Group 3. 
Volume 2 Number 1 Jan-Mar Issue

\section{CONTENT ANALYSIS}

Table 2: Frequency by Format/Month forWhatsapp Group 1

\begin{tabular}{lccccc}
\hline Format & March 2020 & April 2020 & May 2020 & Total & Percentage \\
\hline Text & 33 & 17 & 13 & 63 & 53.8 \\
Comment & 12 & 4 & 1 & 17 & 14.5 \\
Picture & 8 & 1 & 0 & 9 & 7.7 \\
Audio & 1 & 2 & 0 & 3 & 2.6 \\
Video & 10 & 8 & 0 & 18 & 15.4 \\
Link & 5 & 2 & 0 & 7 & 5.9 \\
\hline Total & $69(58.9 \%)$ & $34(29.0 \%)$ & $14(11.9 \%)$ & 117 & 100.0 \\
\hline
\end{tabular}

Source: Content analysis, Epepe, 2020.

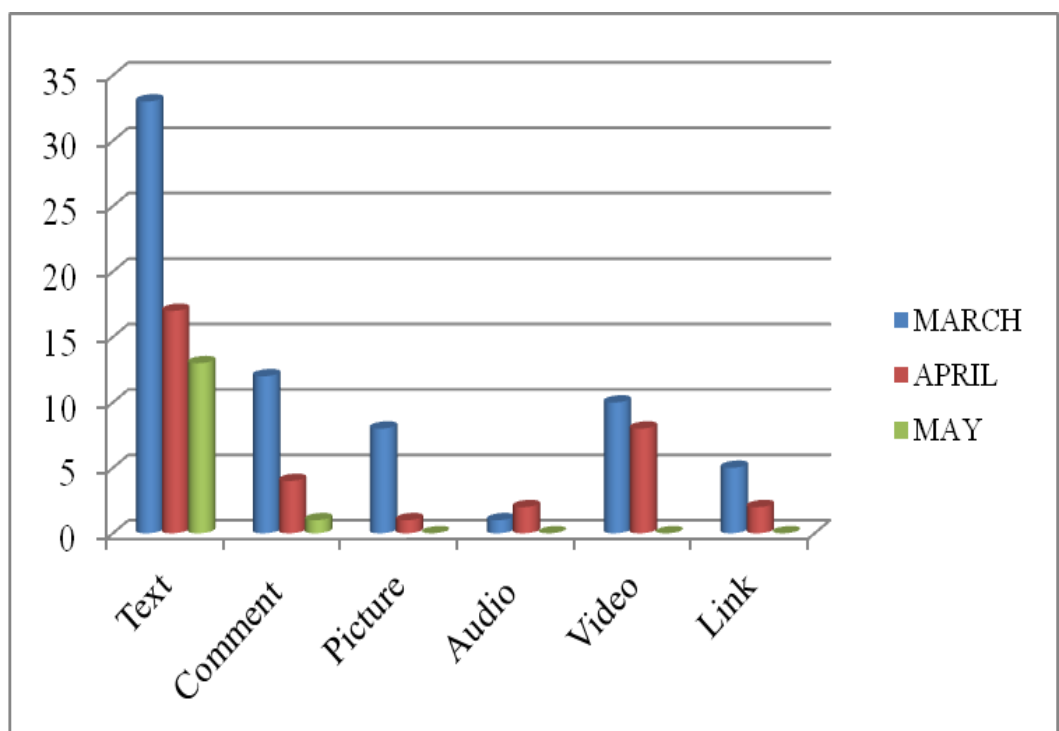

Figure 1. Illustration of frequency of messages by format/month for WhatsApp Group 1.

Table 2 details the frequency of messages by format and month on WhatsApp Group 1. Findings show a total of 117 messages relating to COVID-19 over the three months. March 2020 was the peak month with 69(58.9\%) messages, followed by April with 34(29.0\%) messages, with May 14(11.9\%) recording the least posts. Overall, textual posts recorded the highest number with 63(53.8\%), video messages was second with $18(15.4 \%)$, closely followed by comments with 17(14.5\%). Pictorial messages recorded 9(7.7\%), link posts had 7(5.9\%), the least being audio messages with $3(2.6 \%)$. The result is graphically illustrated in Figure 1. Findings underscore the importance of WhatsApp in disseminating messages in group-based communication. This result agrees with Shahid (2018) and Seufert et al. (2015) who found that WhatsApp has become vital for group-based communication.

Table 3 : Frequency of Messages by Month/Format for Whatsapp Group 2

\begin{tabular}{|c|c|c|c|c|c|}
\hline Format & March & April & May & Total & Percentage \\
\hline
\end{tabular}


Volume 2 Number 1 Jan-Mar Issue

DOI: doi.org/10.47851/naujocommed.v2i1.106

\begin{tabular}{lcclcr}
\hline Text & 5 & 2 & 0 & 7 & 35.0 \\
Comment & 5 & 4 & 0 & 9 & 45.0 \\
Picture & 0 & 0 & 0 & 0 & 0.0 \\
Audio & 0 & 0 & 0 & 0 & 0.0 \\
Video & 0 & 0 & 0 & 0 & 0.0 \\
Link & 4 & 0 & 0 & 4 & 20.0 \\
\hline Total & $\mathbf{1 4 ( 7 0 . 0}$ & $\mathbf{6 ( 3 0 . 0 \%}$ & $\mathbf{0 ( 0 . 0 \% )}$ & $\mathbf{2 0}$ & $\mathbf{1 0 0 . 0}$ \\
& $\mathbf{\%})$ & ) & & & \\
\hline
\end{tabular}

Source: Content analysis, Epepe, 2020.

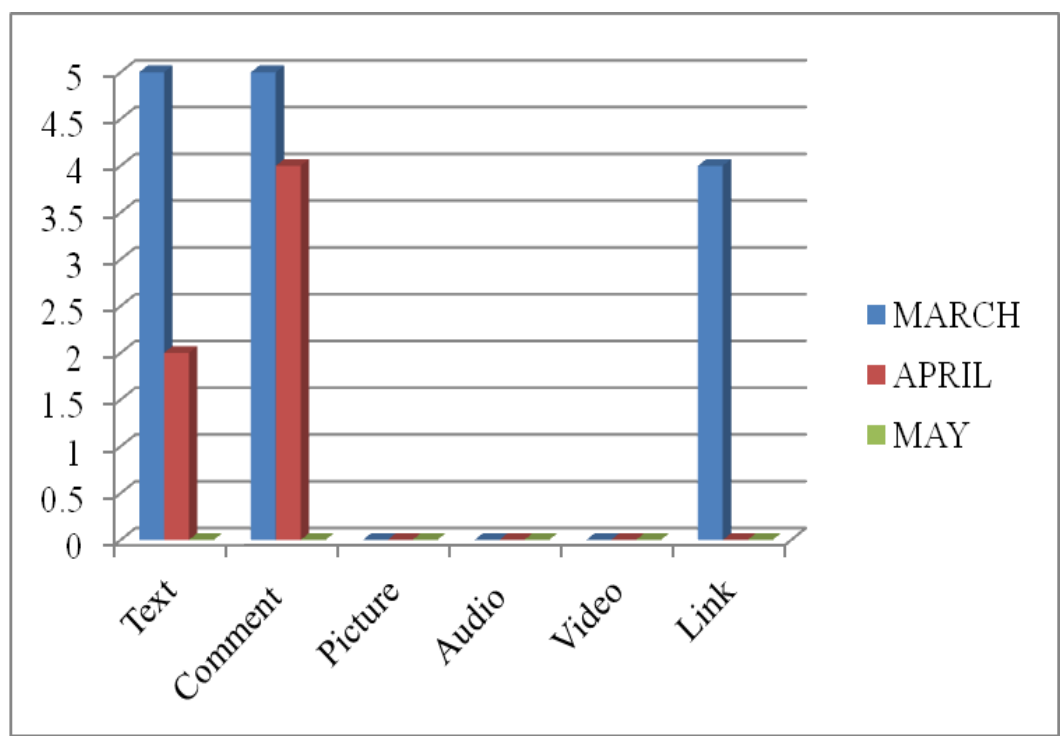

Figure 2. Illustration of frequency of messages by month/format for WhatsApp Group 2.

As evident in Table 3, a total of 20 posts were recorded over the three months, with comment having the highest number 9(45.0\%), text followed with 7(35.0\%) messages and link had 4(20.0\%). Compared to Groups 1 and 3, WhatsApp Group 2 appeared to be quite interactive, as the number of comments and links exceeded those of messages in only text format. However, COVID-19 messages were minimal in Group 2, as there were no messages in picture, video and audio formats. Perhaps, the professional nature and the restrictive administration rules of the group could help explain the result. That being the case, the month of March was more active in terms of COVID-19 posts, with no messages recorded in May 2020. Figure 2 graphically illustrates the results.

Table 4

Frequency of Messages by Format/Month for Whatsapp Group 3

\begin{tabular}{lrrrrc}
\hline Format & March & April & May & Total & Percentage \\
\hline Text & 57 & 24 & 19 & 100 & 60.9 \\
Comment & 17 & 14 & 8 & 39 & 23.7 \\
Picture & 1 & 0 & 0 & 1 & 0.6 \\
Audio & 3 & 0 & 0 & 3 & 1.8 \\
Video & 3 & 0 & 1 & 4 & 2.4 \\
Link & 11 & 6 & 0 & 17 & 10.4 \\
\hline Total & $\mathbf{9 2}$ & $\mathbf{4 4}$ & $\mathbf{2 8}$ & $\mathbf{1 6 4}$ & $\mathbf{1 0 0}$ \\
\hline
\end{tabular}


Volume 2 Number 1 Jan-Mar Issue

DOI: doi.org/10.47851/naujocommed.v2i1.106

Source: Content analysis, Epepe, 2020.

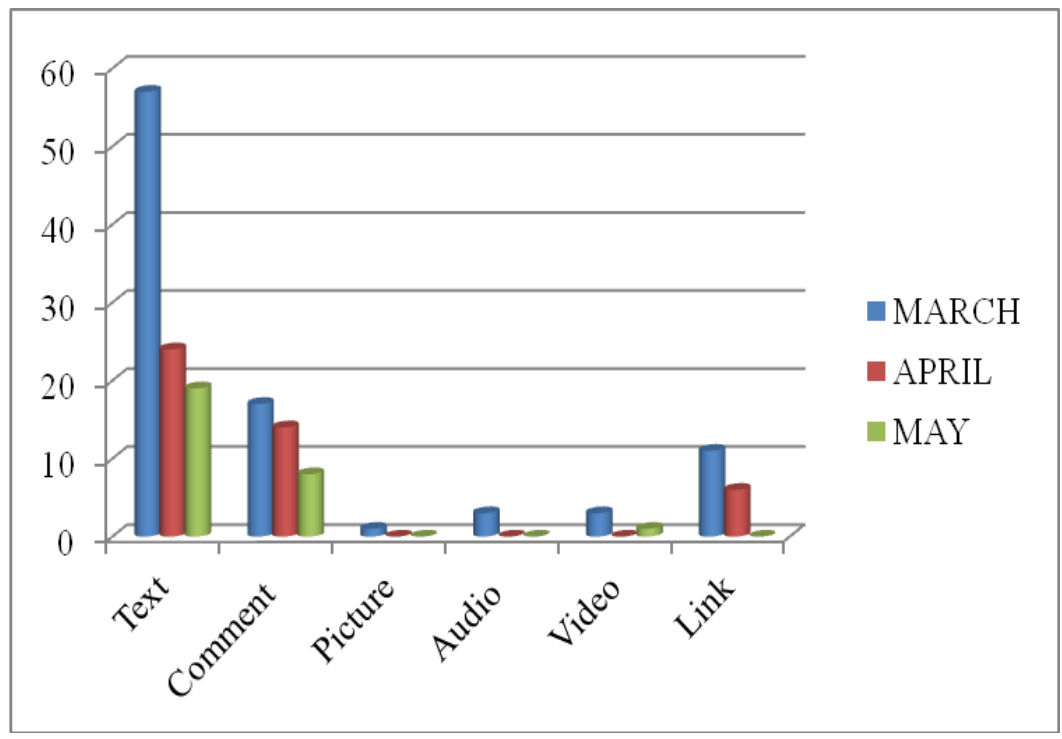

Figure 3. Illustration of frequency of messages by format/month for Whats App Group 3

Table 4 shows that a total number of 164 Covid-19 messages were posted on Whatsapp Group 3 within the 3 months. In order of significance, text-based messages recorded the highest number, with $100(60.9 \%)$ posts, this was followed by comments at $39(23.7 \%)$. Linked messages had $17(10.4 \%)$ posts, video messages had 4(2.4\%), with audio at 3(1.8\%), the least being picture at $1(0.6 \%)$. The highest number of COVID-19 messages was posted in March, followed by April, with the least messages posted in May 2020. Figure 3 further illustrates the result.

Table 5: Dominant Format for COVID-19 Messages on WhatsApp Groups

\begin{tabular}{lccccc}
\hline Format & Group 1 & Group 2 & Group 3 & Total & Percentage \\
\hline Text & 63 & 7 & 100 & 170 & 56.5 \\
Comment & 17 & 9 & 39 & 65 & 21.6 \\
Picture & 9 & 0 & 1 & 10 & 3.3 \\
Audio & 3 & 0 & 3 & 6 & 1.9 \\
Video & 18 & 0 & 4 & 22 & 7.3 \\
Link & 7 & 4 & 17 & 28 & 9.3 \\
\hline Total & $117(38.9 \%)$ & 20 & $164(54.5 \%)$ & 301 & 100.0 \\
& & $(6.6 \%)$ & & & \\
\hline
\end{tabular}

Source: Content analysis, Epepe, 2020. 
Volume 2 Number 1 Jan-Mar Issue

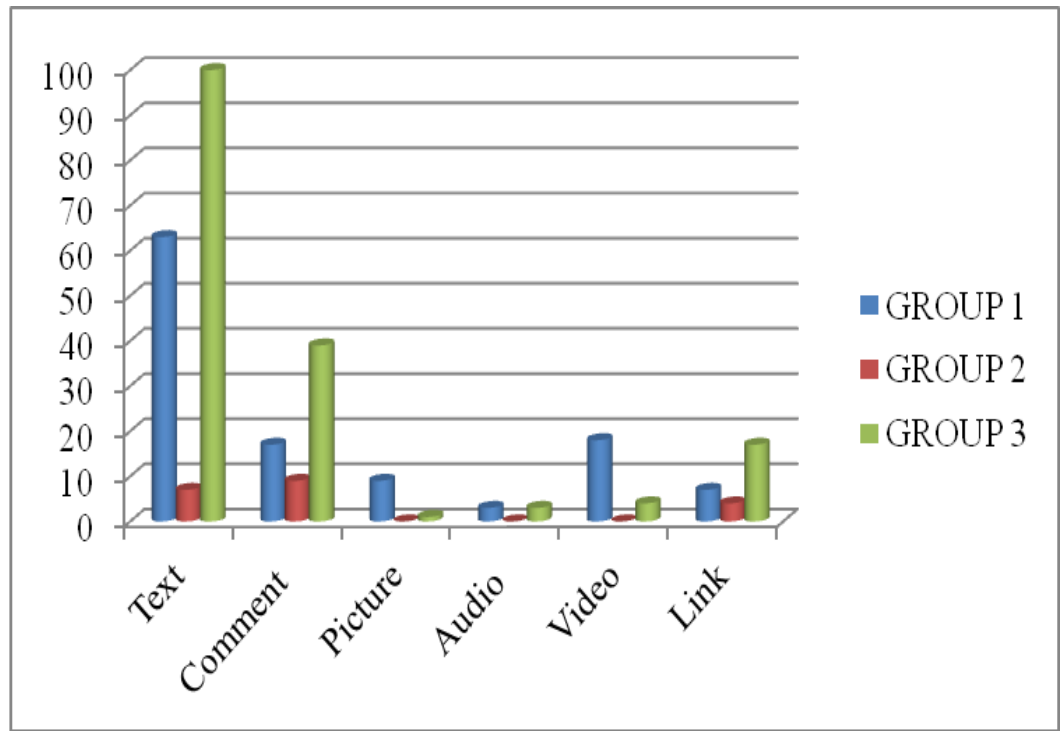

Figure 4. Illustration of dominant format for COVID-19 messages on WhatsApp groups.

Results in Table 5 indicate that a total of 301 messages that relate to Covid-19 were posted on the sampled days of the selected Groups. Out of which, Group 3 topped the chart with 164(54.5\%) messages, Group 1 distantly followed with 117 (38.9\%) messages and Group 2 had the least with $20(6.6 \%)$ messages. Again, in order of significance, more than half 170 $(56.5 \%)$ were in text format, $65(21.6 \%)$ were comments, $28(9.3 \%)$ were posted links, 22(7.3\%) were video messages, $10(3.3 \%)$ were pictures and audio was the least format with $6(1.9 \%)$ messages, This conclusion is text-based messages and comments were the dominant formats used in disseminating COVID-19 messages from March-May 2020. Figure 4 further illustrates the result.

The results suggest that WhatsApp is a multimodal instant messaging platform that affords users options such as text, video, audio, pictures and links. Also, the comment feature enhances feedback and interactivity. The result reported in this study, is consistent with Shahid (2018) submission that major features of WhatsApp include, 'text messages, audio notes, videos, location details, files and many more.

Table 6: Summary of COVID-19 Messages by Month.

\begin{tabular}{lcc}
\hline Month & Frequency & Percentage \\
\hline March & 175 & 58.1 \\
April & 84 & 27.9 \\
May & 42 & 13.9 \\
\hline Total & 301 & 100.0 \\
\hline
\end{tabular}

Source: Content analysis, Epepe, 2020. 
Volume 2 Number 1 Jan-Mar Issue

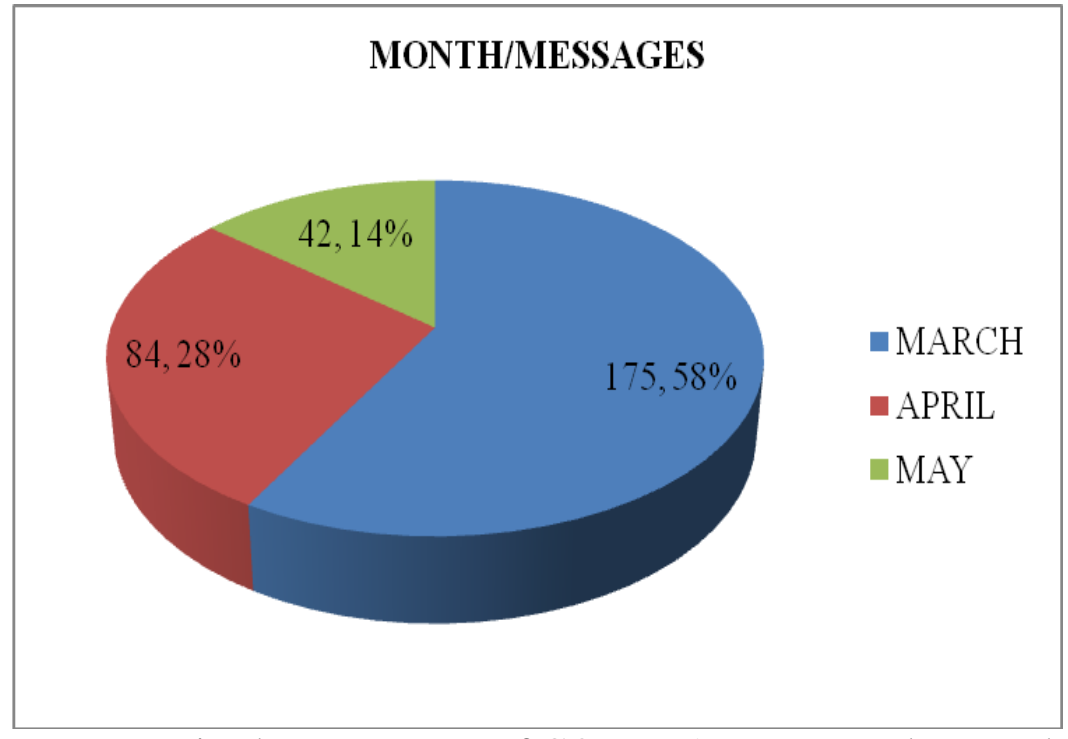

Figure 5. Pie chart summary of COVID-19 messages by month.

As evident in Table 6, the highest number of COVID-19 messages came in March 2020, with 175(58.1\%) messages, distantly followed by April with 84(27.9\%) messages. The least Covid19 messages came in May 2020 with 42(13.9\%) messages. Figure 5 further illustrates the result.

\section{MULTIMODAL DISCOURSE ANALYSIS}

This section aims to provide preliminary evidence on the potential of WhatsApp to inform, misinform or spread rumour. To achieve this, a screenshot of some relevant posts on COVID19 message from the select groups are displayed and analysed in Figures 6-21.

To ensure privacy, the names and numbers of members in each group were edited out.

\section{(a) Credible Information}

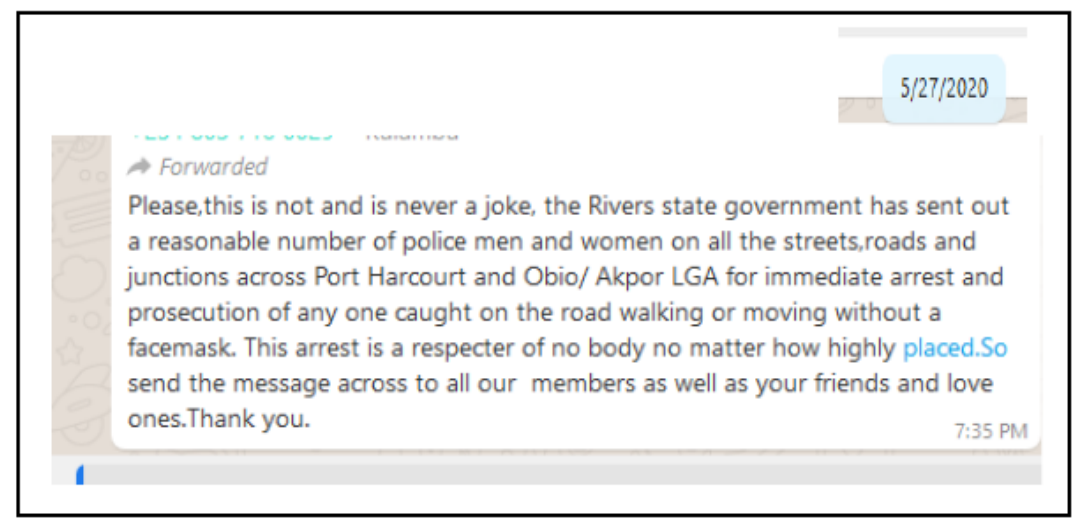

Figure 6. Textual post.

Source: WhatsApp Group 1

Date: $27^{\text {th }}$ May 2020

Time: 7:35 PM

Message Format: Text

Headline: None 
Volume 2 Number 1 Jan-Mar Issue

Figure 6 is a forwarded textual message on enforcement of face mask-wearing to curb the spread of COVID-19 in Port Harcourt and Obio/Akpor Local Government Areas. The message was posted on WhatsApp Group 1 on May 27, 2020, by 7: 35PM. At a glance, the message, which was from an anonymous sender, could have been flagged as misinformation. Though the message was from a second-hand unofficial source, with no headline, it fulfilled the ideational/representational and textual/compositional functions. It was considered to be credible information, as law enforcement agents were observed on the streets carrying out the directive, few days after the message was posted.

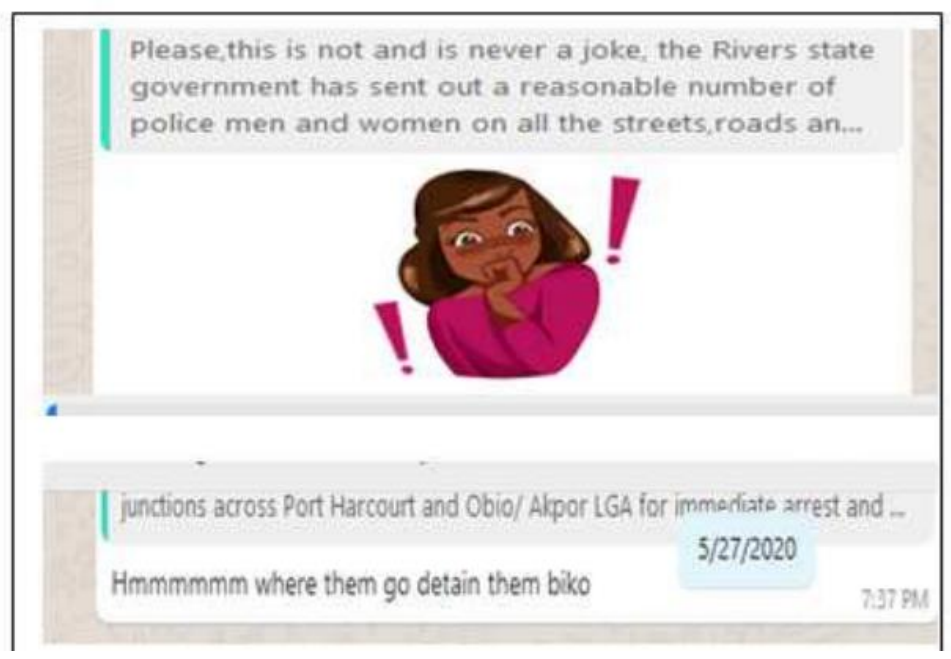

Figure 7. Textual and emoticon comment.

\section{Source: WhatsApp Group 1}

Date: 27 May 2020

Time: 7:37 PM

Message Format: Text, and Emoticon

Headline: None

Figure 7 is a comment in response to the message in Figure 6. The satirical comment "Hmmmmmm where them go detain them biko", provided additional meaning to the pensive/surprised looking emoticon questioning the feasibility of enforcement, as defaulters may outnumber the available spaces in detention centres. The choice of gender of the emoticon is indicative that the commentator might be a woman/lady. It is worthy to note that the comment came at 7: 37PM (2 minutes after the original post in Figure 7). This highlights the speed at which messages and feedback spread on WhatsApp. Nevertheless, one can conclude that the comment fulfils the representational, interactive and compositional functions of multimodal analysis (Kress and van Leeuwen 2006). This finding confirms the interactivity potential of WhatsApp. The emoticon can be termed what Kress and Van Leeuwen (2006) describe as an interactive participant.

A Forworded

Governor Wike announces temporary lifting of lockdown for residents to restock foodstuffs and medicines

Rivers State Governor, Nyesom Ezenwo Wike has announced the temporary lifting of the total lockdown on Obio/Akpor and Port Harcourt Local Government Areas for two days only, with effect from Tuesday 12th May 2020.

Governor Wike made the announcement in a State-Wide broadcast on Sunday night. He said that the total lockdown will be lifted on Tuesday 12th May, 2020 and Wednesday, 13th May, 2020. 
Volume 2 Number 1 Jan-Mar Issue

Figure 8. Textual post on temporary lifting of lockdown.

\section{Source: WhatsApp Group 1}

Date: 11 May 2020

Time: 6:10AM

Format: Text

Headline: "Governor Wike announces temporary lifting of lockdown for residents to restock foodstuffs and medicines"

Figure 8 is an excerpt of an official press release of the Rivers State Government temporary lifting of lockdown for residents to restock foodstuffs and medicines. The message which was originally posted on 10th May 2020 was forwarded to WhatsApp Group 1 on 11 May 2020 at 6:10 AM. The message was sent to the group quite early in the day, probably to prepare group members for the events that usually follow such announcements. This message was found to be credible, particularly because it was signed by a government representative. Besides, the events after the message confirmed the credibility of the message. Specifically, this message fulfilled the representational and compositional functions of multimodal analysis.

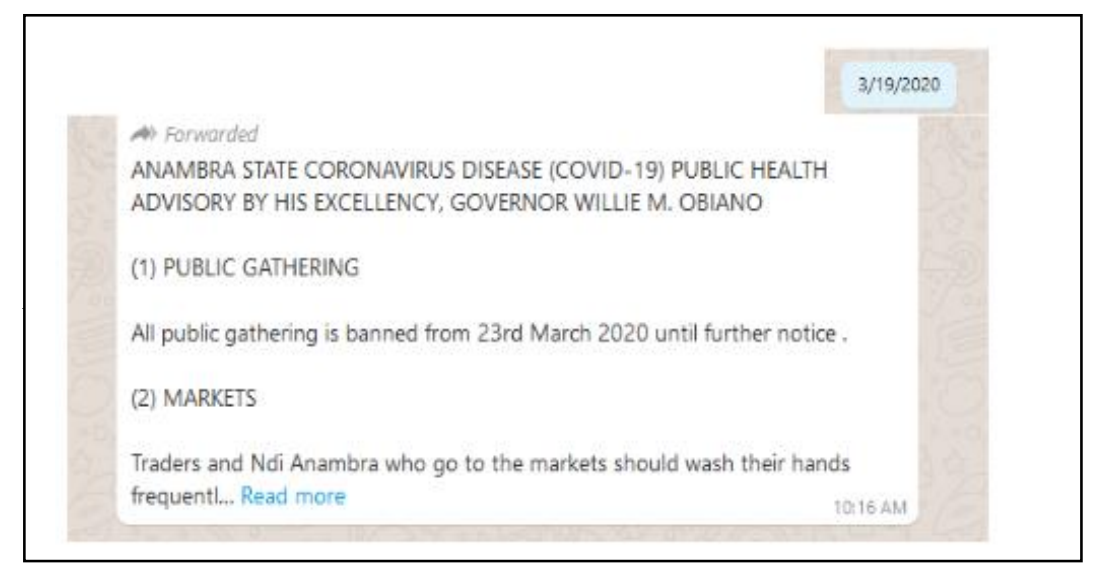

Figure 9. Anambra State Coronavirus public health advisory.

Source: WhatsApp Group 2

Date: 19 March 2020

Time: 10:16AM

Format: Text

Headline: "Anambra State Coronavirus Disease (Covid-19) Public Health Advisory by His Excellency, Governor Willie M. Obiano"

Figure 9 on WhatsApp Group 2 is an excerpt of a textual advisory on Covid-19 by the Anambra State Government. The message posted on the 19th of March 2020, by 10:16 AM had a capitalised headline, emphasising the import of the message. An analysis shows that the headline was consistent with the content of the message, suggesting an element of credibility. The message had representational and compositional meanings. Overall, the message was found to be credible information. 


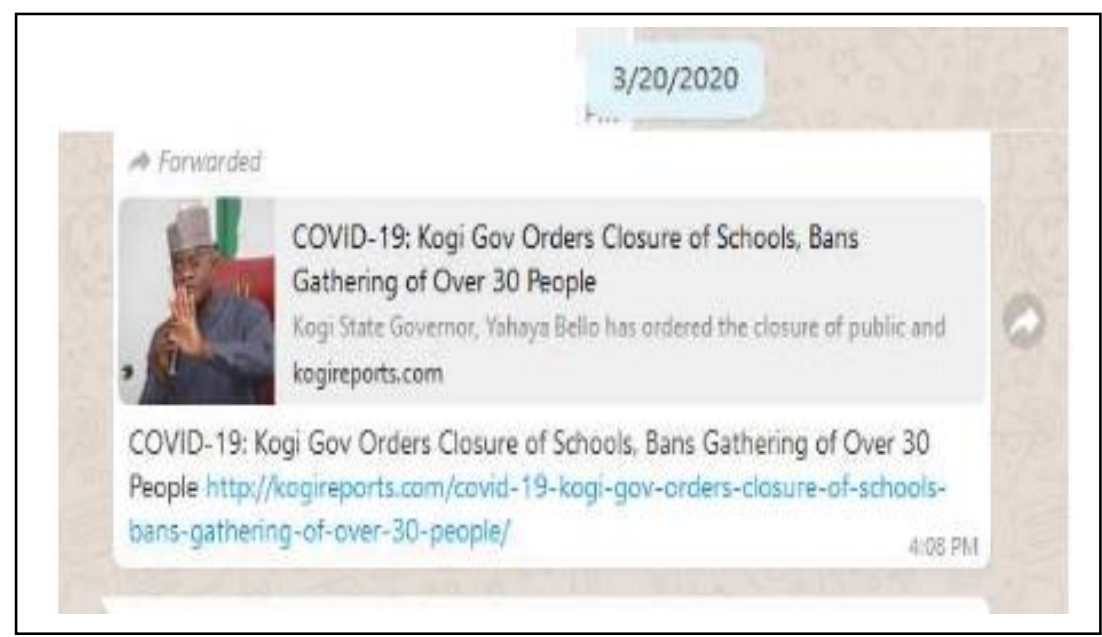

Figure 10. Multimodal message on bans on gathering in public places.

Source: WhatsApp Group 2 (Forwarded from kogireports.com)

Date: 20 March 2020

Time: 4:08AM

Formats: Text, Picture and link

Headline: "Covid-19: Kogi Gov Orders Closure of Schools, Bans Gathering of Over 30 People"

Figure 10 is a multimodal message (text, picture and a web link) forwarded to WhatsApp Group 2 on 20 March 2020. As evidenced in the link, the message was originally reported on kogireports.com. The text served the purpose of emphasising the significance of picture of the $\mathrm{g}$ the governor holding out his hand signifying 'Stop'. The additional web link takes one to the home page of kogireports.com for further details of the ban and thus fulfils interactive functions. The text and picture provided representational and compositional meanings to the message. In conclusion, the message was found to be credible.

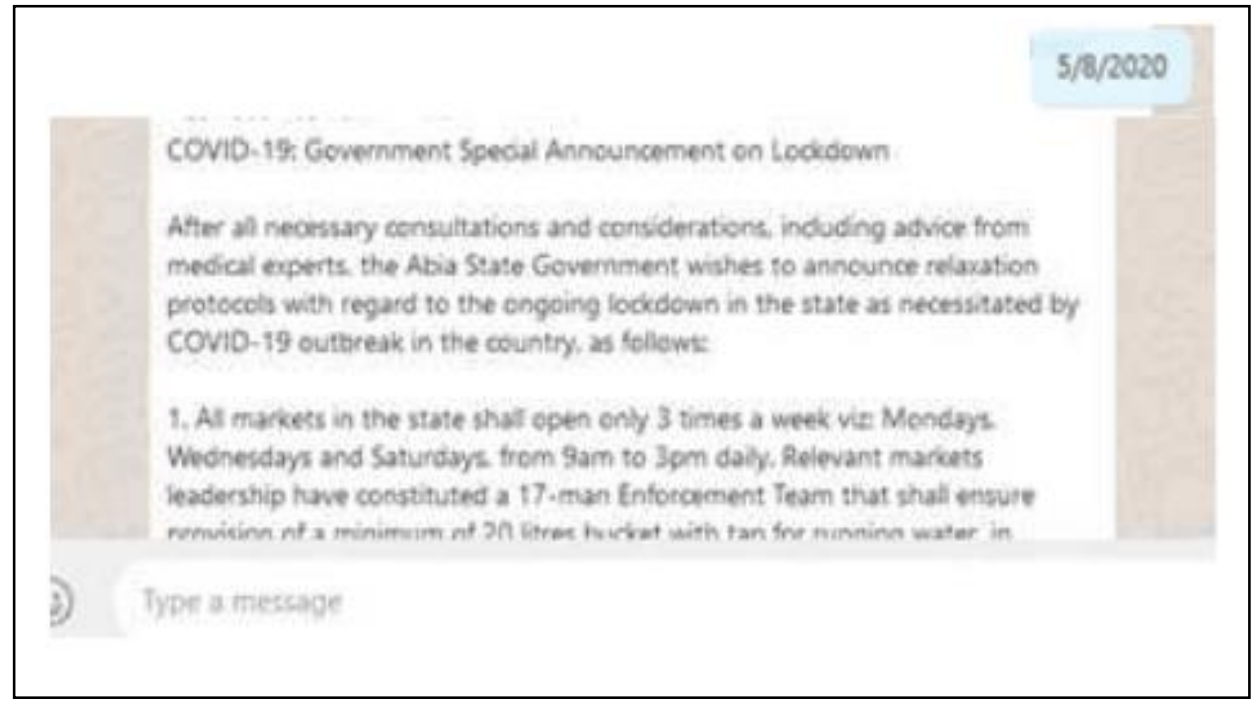

Figure 11. Abia State government lockdown advisory. 
Volume 2 Number 1 Jan-Mar Issue

\section{Source: Whatsapp Group 3}

Date: 8 May 2020

Time sent: 9:01 AM

Format: Text

Headline: "Covid-19: Government Special Announcement on Lockdown"

Figure 11, is a textual excerpt of the Abia State Government's announcement on COVID-19 movement advisory on movement restrictions and rules on public gathering. The message posted on 08/05/2020 by 9:01 AM had a headline combined with capital and initial capitals and was signed by a representative of the State government. The official signatory and consistency of headline and content authenticated credibility of the message. The conclusion reached was that the message had representational and compositional meanings.

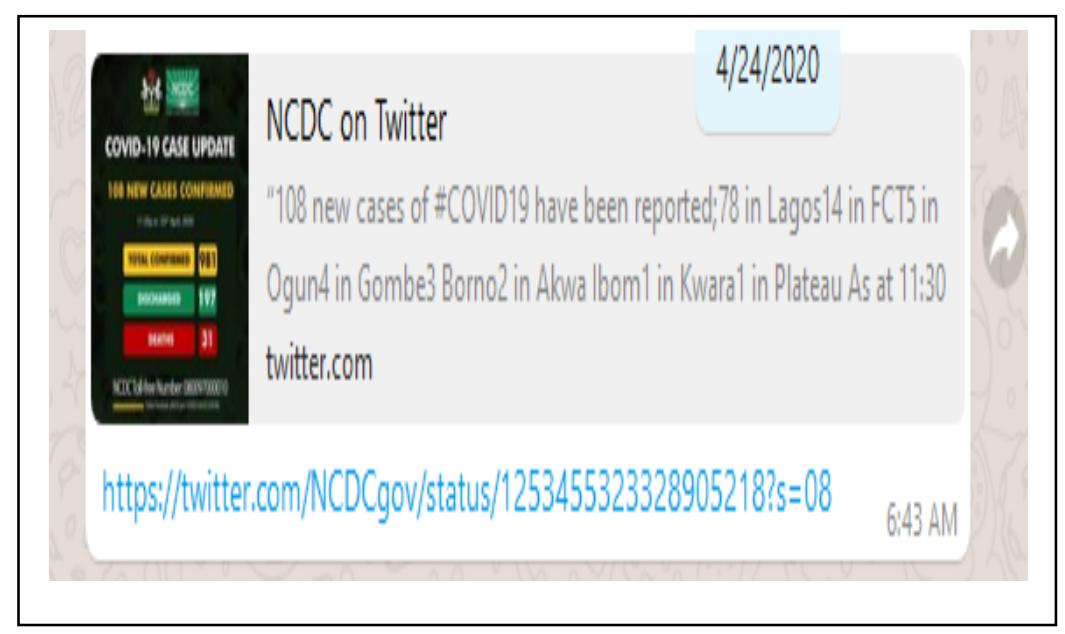

Figure 12. NCDC daily update.

Source: Whatsapp Group 3(Forwared from Twitter)

Date: 4 April 2020

Time: 6:45AM

Format: Text, Picture and Link

Headline: NCDC on Twitter

Figure 12 from WhatsApp Group 3 is a multimodal report on 'COVID -19 CASE UPDATE' across Nigeria. The message was posted $04 / 4 / 2020$ by $6: 45 \mathrm{AM}$, the update reflected figures as of 11:30 PM of 3/4/2020. However, as the headline and link suggest, it was originally forwarded from the Twitter handle of the NCDC. The message served the representational, interactive and compositional functions. Since the NCDC is the official government agency in charge of disease control, the conclusion reached was that the information was credible. 


\section{(b) MISINFORMATION}

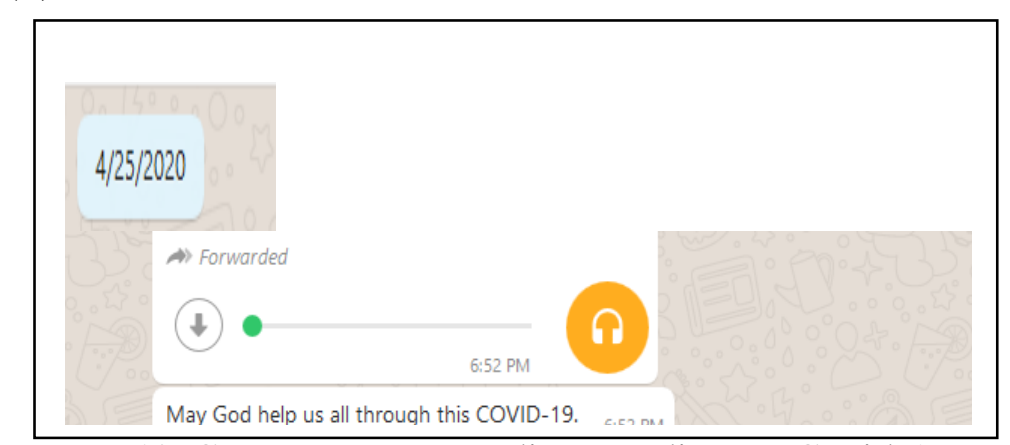

Figure 13. Comment on an audio recording on Covid-19.

Source: WhatsApp Group 1

Time: 6:52PM

Date 25 April 2020

Format: Audio and text

Caption: None

Figure 13 was posted in WhatsApp Group 1on 25 April 2020, illustrating a comment in response to an audio recording (signified by the headpiece). From the response, it is apparent that the video has spread fear and panic about COVID-19. The audio recording was forwarded from an anonymous source, making several unfounded claims about COVID-19. This post fulfilled the interactive function. However, in the dearth of timely information from credible sources, misinformation thrived. This is consistent with the views of Oh et al. (2010) who found that unless proper information is provided to citizens on time, it is likely to stimulate anxiety of citizens to breed rumours.

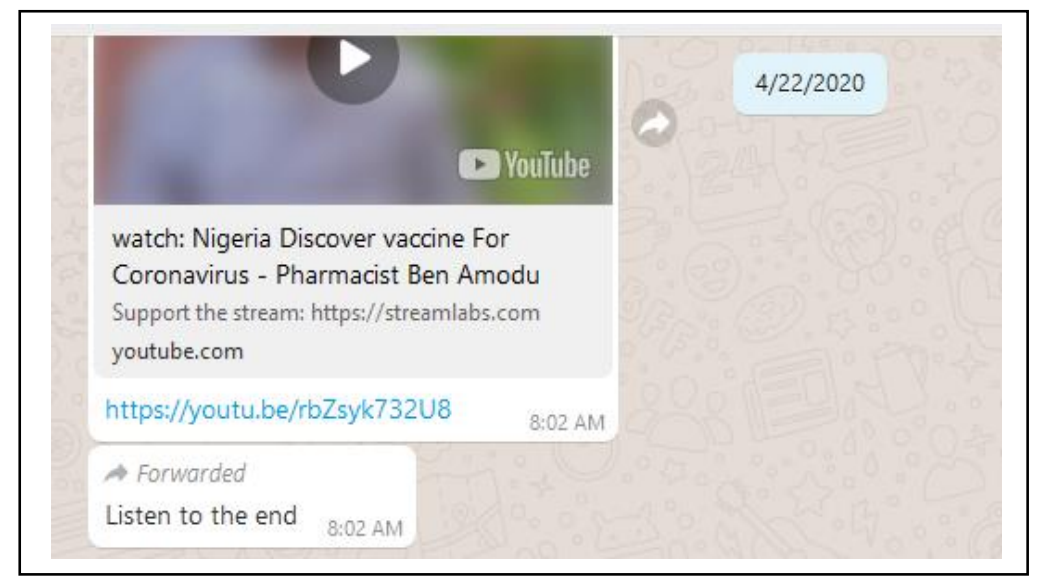

Figure 14. Video post on discovery of Covid-19 vaccine in Nigeria.

Source: WhatsApp Group 1(Culled from YouTube)

Time: 8:02 AM

Date: 22 April 2020 
Volume 2 Number 1 Jan-Mar Issue

Format: Video, text and link

Caption: watch: "Nigeria Discover Vaccine for Coronavirus-Pharmacist Ben Amodu"

Figure 14 depicts a multimodal message shared from YouTube on WhatsApp group 1 on 22 April 2020 at 8:02 AM. The message in the video claimed that a vaccine for coronavirus (see video caption) had been discovered by a Nigerian. An analysis of the video message revealed it was from an unofficial source and there was no approved vaccine for coronavirus at the time of the video. Accordingly, this message had the power to misinform the public. Consistent with the rumour theory, such messages thrived on the anxiety and informational uncertainty (e.g., Oh et al. 2010) of a COVID-19 vaccine. Thus, rumour emerges to fill information gaps, which ultimately breeds misinformation. Nonetheless, the post in Figure 14 appears to fulfil the three main metafunctions of multimodal analysis.

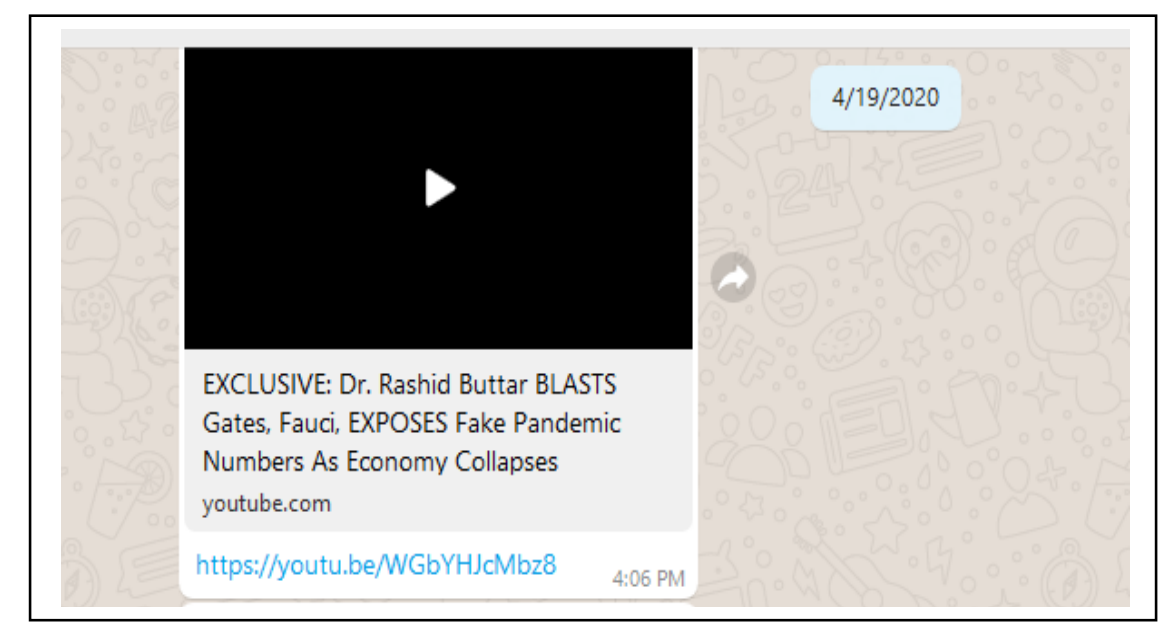

Figure 15. Video post on a conspiracy theory.

Source: WhatsApp Group 1(Culled from YouTube)

Date: 19 April 2020

Time: 4:06 PM

Format: video, text and link

Source: WhatsApp Group 1

Headline: "Exclusive: Dr Rashid Buttar BLASTS Gates, Fauci. EXPOSES Fake Pandemic Numbers As Economy Collapses"

Figure 15 is a multimodal (video, text and link) shared on WhatsApp group 1on 18 April 2020, highlighting a conspiracy theory that emerged in the heat of the first wave of the COVID-19 pandemic. To emphasise the point, the creator of the message on YouTube capitalised the words 'BLASTS' and EXPOSES. While the authenticity of this message is in question as it failed to produce convincing facts, it attracted a comment, "Mindblowing i (sic) must admit...". The rumour mill of such unverifiable messages has far-reaching consequences as its keeps spreading with the town crier effect. While the video and text fulfilled the representational and composition functions, the link provided interactive meanings. 


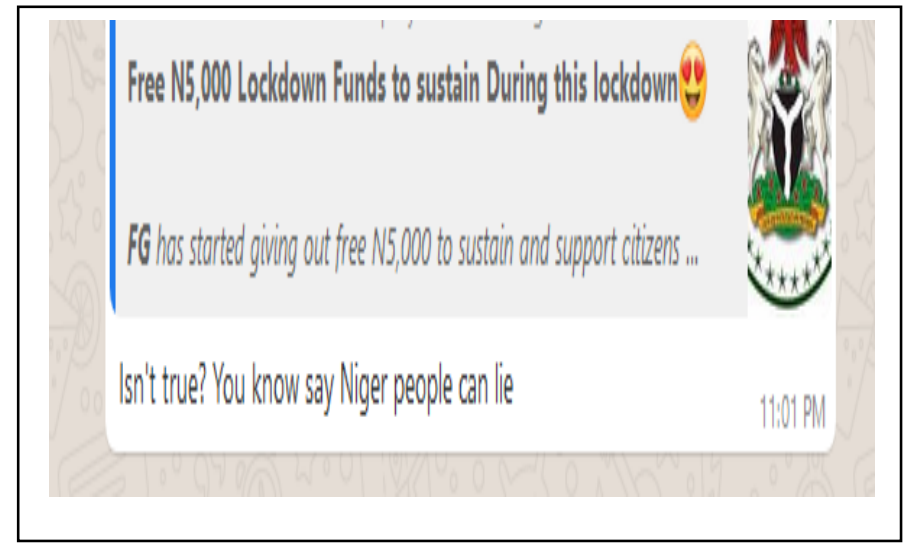

Figure 16: Comment on free funds by the FG.

Source: Whatsapp Group 1

Date: 16 April 2020

Time:11:01 PM

Format: Text, picture, link

Headline: "Free N5,000 Lockdown Funds to sustain during this Lockdown"

Figure 16 was a clear case of misinformation that was forwarded to WhatsApp Group 1 on 16 April 2020 at 11:01 PM. The message had a representational component in the texts that claim that the FG was giving out free $\mathrm{N} 5,000$ as support to citizens during the lockdown. There was a link on how to apply at the end of the post that had interactive meaning. This was found to be false. The message was probably started to exploit the economic hardship, occasioned by the COVID-19 lockdown.

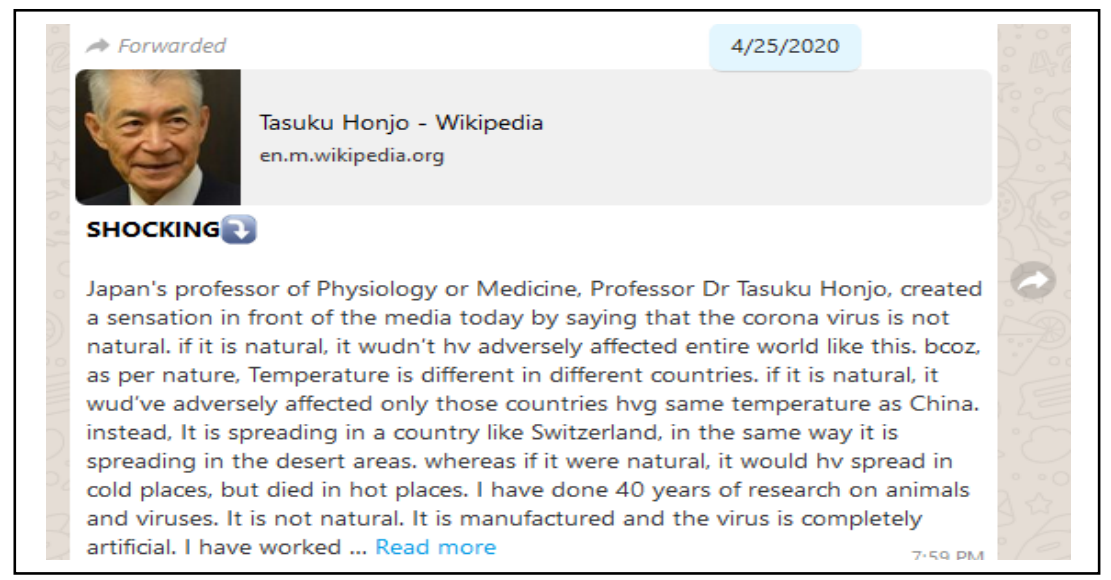

Figure 17. Textual post on manufacturing of Coronavirus.

Source: Whatsapp Group 1(Posted from en.wikipedia.org)

Date: 25 April 2020

Time: 7:59PM 
Volume 2 Number 1 Jan-Mar Issue

Format: Text, Picture and Link

Headline: "SHOCKING"

The message in Figure 17 posted on 24 April 2020 at 7:59 PM had a sensational headline "SHOCKING" in capitals ending with a downward pointing directional arrow. Though the message had a headline and writer, the credibility of the message could be called to question for several reasons. For one, the use of the word "bcoz" instead of "because" and "wudn't hv" instead of "would not have" in a supposedly 'important' and 'professional' message such as this, smacks of amateurish scientific reportage. Besides, the Wikipedia link had no connection to the headline or writer, and there were so many unsupported claims on the expertise of the writer.

The incredibility of the post was reflected in a comment a user posted by 8:10 PM," I'm not sure how true this is". As Rosnow and Fine (as cited in Oh et al. 2010) put it, "disasters and other crises are characterized by high importance, high ambiguity, low critical sensibility, and many rumors".

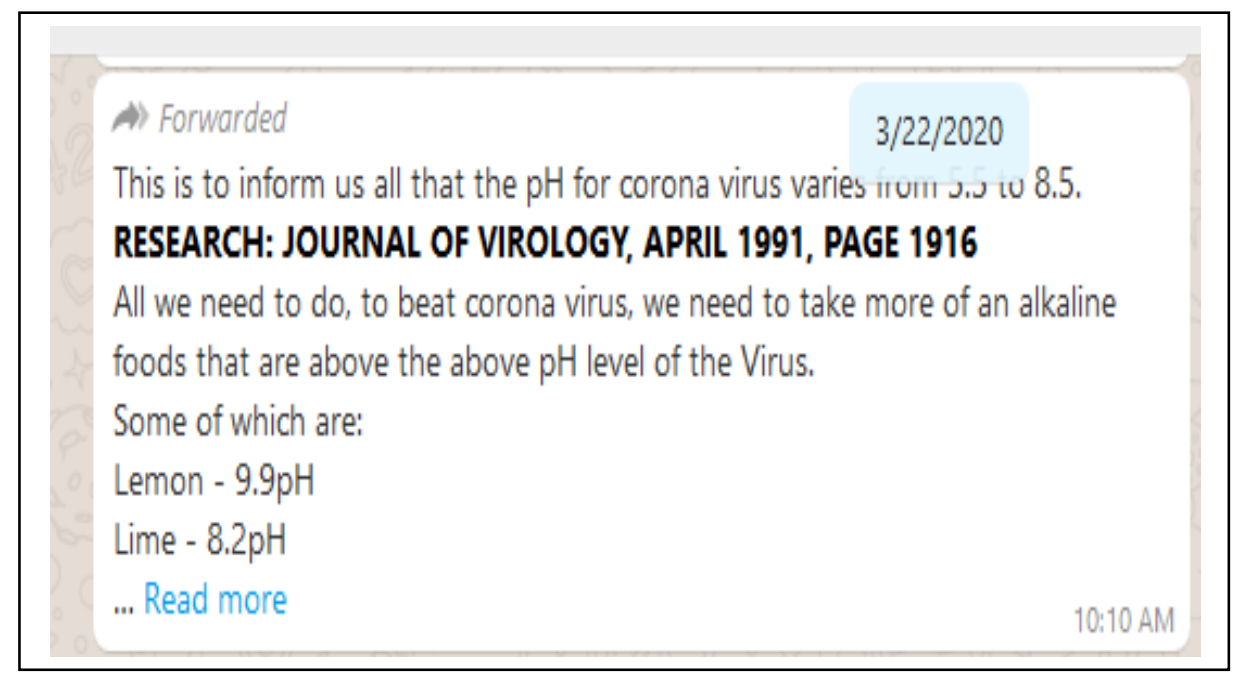

Figure 18. Purported alkaline treatment for Coronavirus.

Source: Whatsapp Group 2

Date: 22nd March 2020

Time sent: 10:10AM

Format: Text

Headline: None

Figure 18 is a textual message forwarded from an anonymous sender to WhatsApp group 2 on 22 March 2020 at 10:10 AM. The message serving representational and compositional meanings claimed that alkaline foods above the $\mathrm{pH}$ level of coronavirus can destroy the virus. Considering the complex nature of the virus, it will be too simplistic to base treatment of coronavirus on intake of alkaline foods. Nonetheless, the direct consequence of the virality of this message was the observed grossly inflated prices of limes and lemons, due to the high demand.

Again, consistent with the rumour theory, anxiety gave power to these kinds of messages to trend and opened the pathways for misinformation. The message can be flagged a 
Volume 2 Number 1 Jan-Mar Issue

misinformation for two main reasons: 1 . The sender is not mentioned; 2 . The cited journal is outdated and not specific to COVID-19, therefore may not be credible.

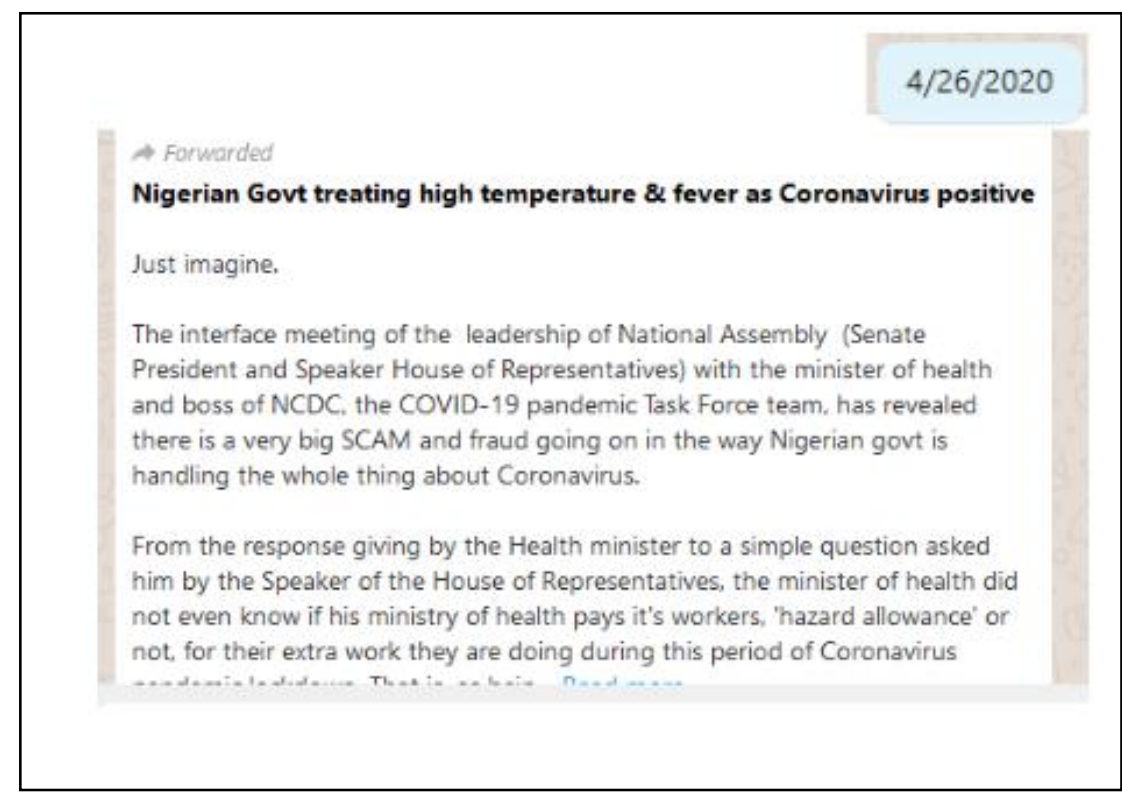

Figure 19. Misinformation of diagnoses of COVID-19.

Source: Whatsapp Group 3

Date: 26 April 2020

Time sent: 9:10PM

Format: Text and Emoticons

Headline: "Nigerian Govt treating temperature \& fever as Coronavirus positive"

Figure 19 was forwarded from an anonymous source to WhatsApp group 3 on 24 April 2020 at 9:10 PM. The message that accused the Nigerian federal government of treating high temperature and fever as a coronavirus was without substantiation. Although the headline and content were consistent, they failed to provide convincing evidence on the allegations. For this reason, this post was considered a classic case of misinformation. Consistent with the rumour theory, unless proper information is provided to citizens promptly, the information gap will be filled by hearsays and misinformation.

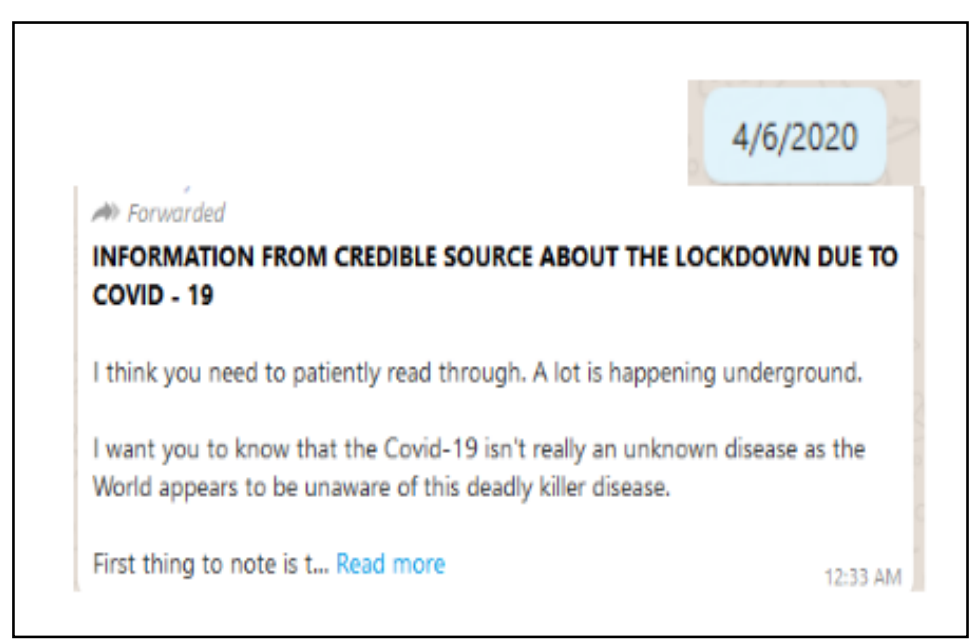


Volume 2 Number 1 Jan-Mar Issue

Figure 20. A conspiracy theory on COVID-19.

Source: Whatsapp Group 3

Date: 6 April 2020

Time sent: 12:33AM

Format: Text, Links

Headline: "INFORMATION FROM CREDIBLE SOURCE ABOUT THE LOCKDOWN DUE TO COVID-19".

Figure 20 was a forwarded message sent to WhatsApp group 3 on 6 April 2020 at 12: 33 AM. The message alleged that the 5G technology was the cause of COVID-19 and vaccines with identification numbers would be forced on people as part of the fulfilment of the new world order. Ironically, the screaming headline "INFORMATION FROM CREDIBLE SOURCE ABOUT THE LOCKDOWN DUE TO COVID-19" filled with religious references. However, it failed to provide convincing evidence in the content when it ended with 'spread the truth'. This message was forwarded many times. Based on the inconsistency of headline and content, this message was flagged as misinformation in this paper.

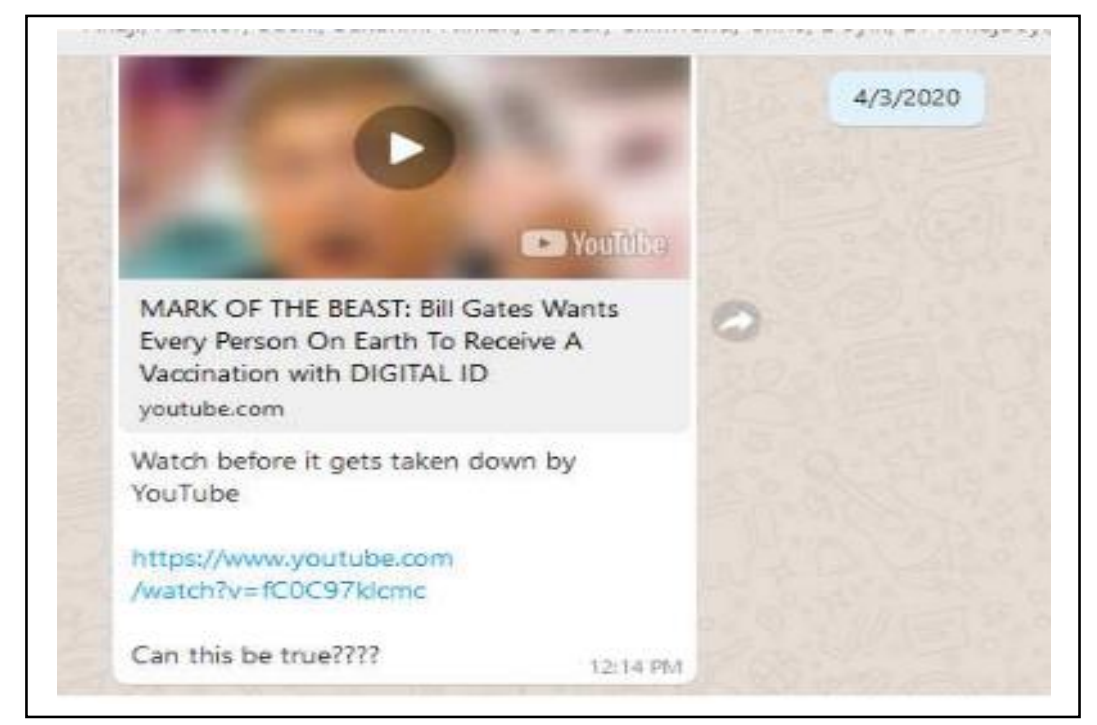

Figure 21. A conspiracy theory of COVID-19 vaccination.

Source: Whatsapp Group 3(Shared from YouTube)

Date: 3 April 2020

Time sent: 12:14PM

Format: Video, Text, Comment and Links

Headline: "MARK OF THE BEAST: Bill Gates Wants Every Person On Earth To Receive a Vaccination with DIGITAL ID"

Figure 21 is a multimodal (video, text, link and comment) message reflecting a recurring narrative in the heat of COVID-19. The message served the representational and compositional 
Volume 2 Number 1 Jan-Mar Issue

DOI: $\underline{\text { doi.org/10.47851/naujocommed.v2i1.106 }}$

functions as depicted in the video and text, while the comment "Can this be true????", provided interactive meanings, as well as questions the credibility of the video post. Grated that there could be some element of truth in certain rumours, but when such messages are not substantiated, it leaves room for doubts. The message forwarded many times was indicative of how rumour thrived in the uncertainty and ambiguity of the pandemic.

\section{CONCLUSION}

This paper set out to analyse COVID-19 messages on select WhatsApp groups from a Nigerian perspective. A total number of 301 messages were analysed. Findings from the content analysis showed that COVID-19 messages with the highest frequency were texts, comments and links. WhatsApp group 3 was the busiest in terms of COVID-19 messages, with group 2 having the least number of messages. Findings also indicated that there was a downward spiral, as COVID-19 messages peaked in March and steeply tapered downwards through April and May 2020, as the novelty wore off.

The multimodal discourse analysis demonstrated the dominance of messages relating to vaccines, prevention, lockdown and several conspiracy theories on COVID-19. From the analysis, it was evident that WhatsApp was a conduit for information dissemination in the COVID-19 pandemic. Nonetheless, like a two-edged sword, findings showed that credible information and misinformation about COVID-19 were spread across the select WhatsApp groups. Very few COVID-19 messages came from official sources, making room for rumour and misinformation to spread. On the whole, messages skewed more in favour of misinformation, rather than credible information.

\section{LIMITATIONS AND IMPLICATION}

The novelty of the COVID-19 pandemic was a major challenge to accessing pertinent literature. Secondly, the manual coding and analysis of data were tedious, as the end-to-end encryption of WhatsApp made it difficult to obtain software that could isolate and analyse the data. This might affect the data set.

Nonetheless, as an exploratory study, this paper contributes to COVID-19 research by exploring the information dissemination potential of WhatsApp within the Nigerian context. Findings could provide some background for the categorisation of group-based messages and set a template for future empirical validation of Rumour Theory on WhatsApp.

\section{REFERENCES}

Allport, G., \& Postman, L. (1946). An analysis of rumor. The Public Opinion Quarterly, 10(4), 501-517.

Allport, G. W., \& Postman, L. (1947). The psychology of rumor. New York: Holt, Rinehart \& Winston.

Barhoumi, C. (2015). The effectiveness of WhatsApp mobile learning activities guided by activity theory on students' knowledge management. Contemporary Educational Technology, 6(3), 221-238.

Baykal, N. (2016). Multimodal construction of female looks: An analysis of mascara advertisements. Dilbilim Araştırmaları Dergisi, 2, 39-59. 
Bordia, P., \& DiFonzo, N. (2004). Problem solving in social interactions on the Internet: Rumor as social cognition. Social Psychology Quarterly, 67, 33-49.

Boyd, C. (2019, July 31). WhatsApp in Africa: A force for good, or digital colonialism? Medium. Retrieved from https://medium.com/swlh/whatsapp-in-africa-3c8626f4980e

Davies, G. (2020, March 24). Coronavirus misinformation on WhatsApp is going viral, despite steps to combat its spread: The messaging service boasts over 2 billion users worldwide. ABC News. Retrieved from https://abcnews.go.com/Health/coronavirusmisinformation-whatsapp-viral-steps-combat-spread/story?id=69688321

Halliday, M. A. K. (1978). Language as social semiotic: The social interpretation of language and meaning. London: Edward Arnold.

Hart, B. (1916).The psychology of rumour. Proceedings of the Royal Society of Medicine, 9, 1-26.

Kazeem Y. (2020, February 28). Nigeria's biggest battle with coronavirus will be beating misinformation. Quartz Africa. Retrieved from https://qz.com/africa/1810219/nigeriascoronavirus-case-may-spark-wave-of-fake-news-and-fears/

Kress, Gunther R., \& van Leeuwen, T. (2006). Reading images: The grammar of visual design (2nd ed). Routledge: London.

Lai L. S. L., \& To, W. M. (2015). Content analysis of social media: a grounded theory approach. Journal of Electronic Commerce Research, 16 (2), 138-152.

Matiashe, F. S. (2020, March 26). WHO is raising coronavirus awareness globally using a WhatsApp bot developed in South Africa. Quartz Africa. Retrieved from https://qz.com/africa/1826415/coronavirus-who-adopts-south-african-whatsapphealth-alert/

Mehta, I. (2020). World Health Organization's WhatsApp bot texts you coronavirus facts. Retrieved July 3, 2020, from https://thenextweb.com/apps/2020/03/20/world-healthorganizations-whatsapp-bot-texts-you-coronavirus-facts/

Oh, O., Kwon, K. H., \& Rao, H. R. (2010). An exploration of social media in extreme events: rumor theory and twitter during the Haiti earthquake 2010. Research paper presented at the Thirty First International Conference on Information Systems, St. Louis. Icis, $231,7332-7336$.

Oyewo, O. O. (2007). Rumour: An alternative means of communication in a developing nation: The Nigerian example. International Journal of African \& African American Studies, VI (1), 1-15.

Romm, T. (2020, March 2). Fake cures and other coronavirus conspiracy theories are flooding WhatsApp, leaving governments and users with a 'sense of panic'. The Washington Post. Retrieved 
https://www.washingtonpost.com/technology/2020/03/02/whatsapp-coronavirusmisinformation/

Rosnow, R. L. (1980). Psychology of rumor reconsidered. Psychological Bulletin, 87(3), 578-591. https://doi.org/10.1037/0033-2909.87.3.578

Rosnow, R. L., Esposito, J. L., \& Gibney, L. (1988). Factors influencing rumor spreading: replication and extension. Language \& Communication, 8 (1), 29-42.

Rosnow, R. L., \& Foster, Eric, K. (2005).Rumor and gossip research. Psychological Science Agenda, 19 (4), 1-4.

Seufert M., Schwind A., Hoßfeld T., Tran-Gia P. (2015). Analysis of group-based communication in WhatsApp. In: Agüero R., Zinner T., García-Lozano M., Wenning BL., Timm-Giel A. (Eds.), Mobile networks and management. MONAMI. Lecture Notes of the Institute for Computer Sciences, Social Informatics and Telecommunications Engineering, 158. Springer, Cham. https://doi.org/10.1007/9783-319-26925-2_17

Shahid, S. (2018). Content analysis of WhatsApp conversations: An analytical study to evaluate the effectiveness of Whatsapp application in Karachi. International Journal of Media, Journalism and Mass Communications 4(1), 14-26.

Shibutani, T. (1966). Improvised news: A sociological study of rumor. Indianapolis, IN: Bobbs-Merrill.

WhatsApp (2020). About WhatsApp. Retrieved August 27, 2020, from, https://www.whatsapp.com/about/

World Health Organisation (2020). WHO Health Alert brings COVID-19 facts to billions via WhatsApp. Retrieved December 22, 2020, fromhttps://www.who.int/newsroom/feature-stories/detail/who-health-alert-brings-covid-19-facts-to-billions-viawhatsapp 